\title{
Crypt Organoid Culture as an In Vitro Model in Drug Metabolism and Cytotoxicity Studies
}

\author{
Wenqi Lu, Eva Rettenmeier, Miles Paszek, Mei-Fei Yueh, Robert H. Tukey, Jocelyn Trottier, \\ Olivier Barbier, and Shujuan Chen
}

Laboratory of Environmental Toxicology, Department of Pharmacology, University of California, San Diego, La Jolla, California (W.L., E.R., M.P., M-F.Y., R.H.T., S.C.); and Laboratory of Molecular Pharmacology, CHU de Quebec Research Centre and Faculty of Pharmacy, Laval University, Québec (Québec), Canada (J.T., O.B.)

Received March 13, 2017; accepted April 27, 2017

\section{ABSTRACT}

The gastrointestinal tract is enriched with xenobiotic processing proteins that play important roles in xenobiotic bioactivation, metabolism, and detoxification. The application of genetically modified mouse models has been instrumental in characterizing the function of xenobiotic processing genes (XPG) and their proteins in drug metabolism. Here, we report the utilization of three-dimensional crypt organoid cultures from these animal models to study intestinal drug metabolism and toxicity. With the successful culturing of crypt organoids, we profiled the abundance of Phase I and Phase II XPG expression, drug transporter gene expression, and xenobiotic nuclear receptor (XNR) gene expression. Functions of XNRs were examined by treating crypt cells with XNR prototypical agonists. Real-time quantitative polymerase chain reaction demonstrated that the representative downstream target genes were induced.
These findings were validated from cultures developed from XNRnull mice. In crypt cultures isolated from $\mathrm{Pxr}^{-/-}$mice, pregnenolone $16 \alpha$-carbonitrile failed to induce Cyp3a11 gene expression; similarly, WY14643 failed to induce Cyp4a10 in the Ppara ${ }^{-/-}$crypts. Crypt cultures from control $\left(U g t 1^{F / F}\right)$ and intestinal epithelial cell (IEC) specific Ugt1 null mice $\left(U g t^{\Delta I E C}\right)$ were treated with camptothecin-11, an anticancer prodrug with severe intestinal toxicity that originates from insufficient UGT1A1-dependent glucuronidation of its active metabolite SN-38. In the absence of Ugt1 gene expression, Ugt1 ${ }^{\text {IIEC }}$ crypt cultures exhibit very limited production of $\mathrm{SN}-38$ glucuronide, concordant with increased apoptosis in comparison with Ugt1 ${ }^{F / F}$ crypt cultures. This study suggests crypt organoid cultures as an effective in vitro model for studying intestinal drug metabolism and toxicity.

\section{Introduction}

The gastrointestinal (GI) tract is lined with epithelial cells that express an abundance of xenobiotic or drug metabolizing enzymes (DMEs) in addition to efflux and influx transporters. Thus, the absorption of xenobiotics and drugs are subjected to metabolism by DMEs localized in the mature enterocyte. This process contributes significantly to bioactivation, metabolism, and detoxification of drugs, all of which are associated with the outcome of drug efficacy and safety. A greater appreciation attributed to the GI tract and drug metabolism has been achieved by examining drug metabolism and toxicity in knockout animal models or fully humanized animal models. For example, human CYP3A4 is considered by many to be one of the most versatile of the CYPs involved in drug metabolism because it accounts for the metabolism of almost half of all prescribed medications (Zanger et al., 2008). Van Herwaarden AE et al. (van Herwaarden et al., 2007) and Van

This work was supported by National Institutes of Health National Institute of Environmental Health Sciences [Grants ES024818 and ES010337] and the National Institute of General Medical Sciences [Grant GM086713].

https://doi.org/10.1124/dmd.117.075945.
Waterschoot RA et al. (van Waterschoot et al., 2008, 2009) generated intestine- and liver-specific expression of human CYP3A4 in a Cyp3a-null background, demonstrating intestinal CYP3A4 activity had a profound impact on systemic exposure of the anticancer drug docetaxel following its oral administration. Camptothecin (CPT)-11 (Irinotecan), is a prodrug that is hydrolyzed by carboxylesterase (CES) in different tissues to form the active topoisomerase inhibitory metabolite SN-38 (Kaneda et al., 1990; Sugimoto et al., 1990), which is further metabolized by UGT1A1-dependent glucuronidation to form an SN-38 glucuronide (SN-38G) (Iyer et al., 1998). Classically, the bioactivation and detoxification of CPT-11 have been credited primarily to hepatic metabolism (Alimonti et al., 2004; Michael et al., 2006). However, recent studies have confirmed that intestinal CES2 has a greater affinity toward CPT-11 in comparison with liver CES1 (Hatfield et al., 2011). With the development of $U g t 1^{F / F}$ mice, deletion of the $U g t 1$ locus in intestinal epithelial cells $\left(U g t 1^{\Delta I E C}\right)$ produced severe CPT-11-induced intestinal toxicity in comparison with $U g t 1^{F / F}$ mice or mice with a liver-specific $U g t 1$ deletion $\left(U g t 1^{\triangle H E P}\right)$ (Chen et al., 2013). This result highlighted that UGT1A1 expression in intestinal tissue is critical in preventing SN-38-induced toxicity.

ABBREVIATIONS: AhR, aryl hydrocarbon receptor; BNF, $\beta$-naphthoflavone; CAR, constitutive androstane receptor; CES, carboxylesterase; CYP, cytochrome P450; DHA, docosahexaenoic acid; DMEs, drug metabolism enzymes; Gl, gastrointestinal; IEC, intestinal epithelial cell; ISC, intestinal stem cell; KO, knockout; PCN, pregnenolone $16 \alpha$-carbonitrile; PPAR, peroxisome proliferator-activated receptor; PXR, pregnane X receptor; RTqPCR, reverse transcription quantitative polymerase chain reaction; SN-38G, SN-38 glucuronide; TCDD, 2,3,7,8-tetrachlorodibenzo- $p$-dioxin; TCPOBOP, 4-Bis-[2-(3,5-dichloropyridyloxy)]benzene; UGT, UDP-glucuronosyltransferase; XNR, xenobiotic nuclear receptors; XPG, xenobiotic processing gene. 
Given the importance of the GI tract and the beneficial application of genetically modified mouse models to examine drug metabolism and toxicity, the development of primary cells cultured from these mice to examine gene expression and toxicity will provide an important tool to complement in vivo animal experiments. Sato et al. (2009) established long-term culture conditions in which one single Lgr5+ stem cell embedded in matrix gel can independently generate villus-like epithelial domains with the presence of all differentiated IECs. The threedimensional culture is a continuously expanding, self-organizing structure that is reminiscent of normal gut. This result has been popularly applied in the study of crypt-villus biology, regenerative medicine, and gene therapy (Sato and Clevers, 2013; Grabinger et al., 2014; Ranga et al., 2014), but its applications to investigate intestinal epithelial cellspecific xenobiotic metabolism has been lacking. In this article, we report the application of crypt organoid cultures from genetically modified mice as a model to examine gene expression and drug metabolism.

\section{Materials and Methods}

Reagents. WY14643 [4-chloro-6-(2,3-xylidino)-2-pyrimidinylthioacetic acid], pregnenolone $16 \alpha$-carbonitrile (PCN), 1,4-Bis-[2-(3,5-dichloropyridyloxy)]benzene (TCPOBOP), phenobarbital, docosahexaenoic acid (DHA), and $\beta$-naphthoflavone (BNF), $N$-acetylcysteine, and CPT-11 standard were from Sigma-Aldrich (St. Louis, MO). SN-38 and T0901317 were purchased from Cayman Chemical Company (Ann Arbor, MI). SN-38 glucuronide was from Santa Cruz Biotechnology (Santa Cruz, CA). Internal standards deuterated d10-CPT-11 and d3SN-38 were purchased from Toronto Research Chemicals (Toronto, Ontario, Canada). 2,3,7,8-Tetrachlorodibenzo- $p$-dioxin (TCDD) was obtained from the National Institutes of Health National Cancer Institute, Chemical Carcinogen Reference Standard Repository (Bethesda, MD). Matrigel basement membrane matrix was purchased from BD Biosciences (Bedford, MA). Advanced DMEM/F12 medium and the supplements, including GlutaMax, Hepes, penicillin streptomycin, mouse EGF, N2, and B27 supplements, were purchased from Thermo Fisher Scientific (Waltham, MA); mouse Noggin was from Peprotech (Rocky Hill, NJ). HEK-293 cells producing R-Spondin 1 protein (293T-HA-Raspol_Fc cell line) was a generous gift from the Dr. Calvin Kuo laboratory at Stanford University (Ootani et al., 2009). The cells were cultured and passaged per standard protocol. For collecting R-Spondin 1 conditioned media, 293T-HA-Raspol_Fc cells at approximately $75 \%$ confluency were changed to advanced DMEM/F12 medium and cultured for another week. Medium was then collected by passing through $0.22 \mu \mathrm{m}$ sterile filter.

Animals. C57BL/6J mice were purchased from Charles River Laboratories (Raleigh, NC). Intestinal-specific $U g t 1$ deletion mice $\left(U g t 1^{\Delta I E C}\right)$ were generated in our laboratory (Chen et al., 2013). Ppard $^{-1-}$ mice were purchased from Jackson Laboratories (Bar Harbor, ME) (Lee et al., 1995). $\mathrm{Pxr}^{-/-}$and $\mathrm{Car}^{-/-}$ mouse models were a kind gift from Drs. Ron Evans (Laboratory at Salk Institute, La Jolla, CA) (Xie et al., 2000) and Masahiko Negishi (Ueda et al., 2002; Yamazaki et al., 2005) (National Institute of Environmental Health Sciences), respectively. The proposed mouse experiments have been approved per the procedures as set by the University of California San Diego Institutional Animal Care and Use Committee. All the proposed mouse strains were housed in a pathogen-free facility with automated temperature control and a 12/12-hour light/dark cycle.

Isolation of Crypt Cells and Organoid Culture. Intestinal crypt cell isolation and organoid culturing were carried out according to previous publications (Sato et al., 2009; Sato and Clevers, 2013) with several modifications. Briefly, mouse small intestine was dissected, cut longitudinally, and washed briefly by ice-cold Dulbecco's phosphate-buffered saline (DPBS). The tissue was further dissected into small pieces and incubated in DPBS containing $2 \mathrm{mM}$ EDTA at $4^{\circ} \mathrm{C}$ with gentle shaking. One hour later, the EDTA solution was removed, and $10 \%$ fetal bovine serum in DPBS buffer added followed by vigorously shaking to release villi and crypt cells. The cell solution was passed through tea filter to remove tissue debris, and then further filtered through a $70 \mu \mathrm{m}$ cell strainer. The filtrate was centrifuged at $1000 \mathrm{~g}$ for 10 minutes at $4^{\circ} \mathrm{C}$, and the cell pellet washed twice by DPBS. Crypt cells were counted. Approximately
1000 crypts were suspended into $50 \mu 1$ ice-cold Matrigel and plated into prewarmed 24-well tissue culture plates. Ten minutes after the incubation, $0.5 \mathrm{ml}$ of complete growth medium (advanced DMEM with GlutaMax, Hepes, penicillin/streptomycin, $\mathrm{N} 2$ and B27 supplements, with $2.5 \mathrm{mM} \mathrm{N}$-acetylcysteine, $0.1 \mu \mathrm{g} / \mathrm{ml}$ mouse Noggin, $0.05 \mu \mathrm{g} / \mathrm{ml}$ mouse EGF, and $10 \%$ of R-Spondin 1-conditioned medium) was added. The growth of crypt organoids was monitored. Mouse EGF was added every other day. Fresh medium was added every 4 days. Cells were normally ready for passage every 7 days. Crypt cells were exposed to various chemicals on day 4 and, after 24 hours, the cells were collected in triplicate for further analysis. The results were described as the average \pm S.E.M., which represent multiple independent experiments with compatible data. Student's $t$ test was used for statistical analysis.

RNA Preparation and Reverse Transcription Quantitative Polymerase Chain Reaction Analysis. Culture medium was removed, and the plates were kept on ice. Ice-cold DPBS was added to break up the Matrigel and the organoids released by pipetting several times through P1000 tips. Crypt cells were collected by centrifugation. Cell pellets were then incubated with $1 \mathrm{ml}$ of TRIzol reagent and RNA isolated as outlined by TRIzol kit. RNA concentrations were determined with a Nanodrop Lite spectrophotometer (Thermo Scientific). Reverse transcription was performed by using $1 \mu \mathrm{g}$ of RNA and following instructions from the iScript cDNA Synthesis Kit (BioRad, Hercules, CA). Real-time quantitative polymerase chain reaction (RT-qPCR) experiments were carried out on a CFX96 quantitative polymerase chain reaction (qPCR) system (BioRad) by using Ssoadvanced SYBR Green reagent (BioRad). Primers were designed through mouse primer depot (https://mouseprimerdepot.nci.nih.gov/). Transcription levels were quantified with the $\mathrm{Ct}$ value normalized to mouse cyclophilin $(\mathrm{Cph})$.

Protein Preparation and Western Blots. Cells were released from Matrigel. Cell lysates were prepared in a RIPA buffer. After protein concentration determination, protein samples were subjected to gel electrophoresis by using Nupage $4-12 \%(\mathrm{wt} / \mathrm{vol})$ Bis-Tris gradient gel (ThermoFisher). Western blots were developed and imaged using a ChemiDoc Touch Imaging System (BioRad). The following antibodies were used: goat anti UGT1A (Santa Cruz, sc-27418), rabbit anti-cleaved caspase 3 (Cell Signaling, \#9661; Danvers, MA), and anti- $\alpha$ tubulin (Sigma, T9026).

Liquid Chromatography/Mass Spectrometry Studies of CPT-11, SN-38, and SN-38G. Sample preparation was performed as previously described (Marangon et al., 2015). Media or cell lysates were centrifuged, and the supernatants were added with $0.1 \%$ acetic acid (v/v 1;3) containing the internal standards deuterated d10-CPT-11 and d3-SN-38 at $15 \mathrm{ng} / \mathrm{ml}$. Standards were prepared by spiking $10 \mu \mathrm{l}$ of working solutions in $90 \mu \mathrm{l}$ of blank medium, which sustains subsequent treatments as samples. Samples were centrifuged and $1 \mu \mathrm{l}$ of the supernatants was injected for analysis by a Prominence HPLC (Shimazu, Tokyo, Japan) coupled with an API4000 mass spectrometer (Sciex, Framingham, MA). Separation was achieved using a Gemini C18 column (100X4.6 mm, $3 \mu \mathrm{M}$; Phenomenex, Torrance, CA), and mass spectrometry analysis was achieved using positive mode with ion spray voltage set at $5000 \mathrm{~V}$ and a source temperature of $600^{\circ} \mathrm{C}$. The following transitions were used for quantification in multiple reaction monitoring (MRM) mode: CPT-11: $\mathrm{m} / \mathrm{z} 587.4 \rightarrow 124.2 ; \mathrm{SN}-38: \mathrm{m} / \mathrm{z} 393.3 \rightarrow 349.3$; SN-38G: $\mathrm{m} / z, 569.3 \rightarrow 392.3$; and the internal standards d10-CPT-11: $\mathrm{m} / \mathrm{z}$ $597.4 \rightarrow 133.3$; and d3-SN-38: $\mathrm{m} / \mathrm{z} 396.2 \rightarrow 352.2$.

\section{Results}

Development of Crypt Organoids and the Expression of Drug Metabolism Enzymes. Each crypt culture contained multiple cells and normally formed spherical structures on the first day after the incubation (Fig. 1A), followed by budding. Small buds usually could be visualized in 2-4 days after the incubation. The crypt region underwent continuous budding events; by day 5 after incubation, the lumen of organoids became distorted and dark, which were filled with matured enterocytes or apoptotic cells (Fig. 1A). Well-developed organoids were collected between days 7 and 10 after cells were passaged, and RT-qPCR was conducted to investigate gene expression patterns. As demonstrated in Fig. 1B, Phase I and Phase II XPGs along with transporter genes were identified in mature crypt organoids. Cytochrome P450 (Cyp) gene 


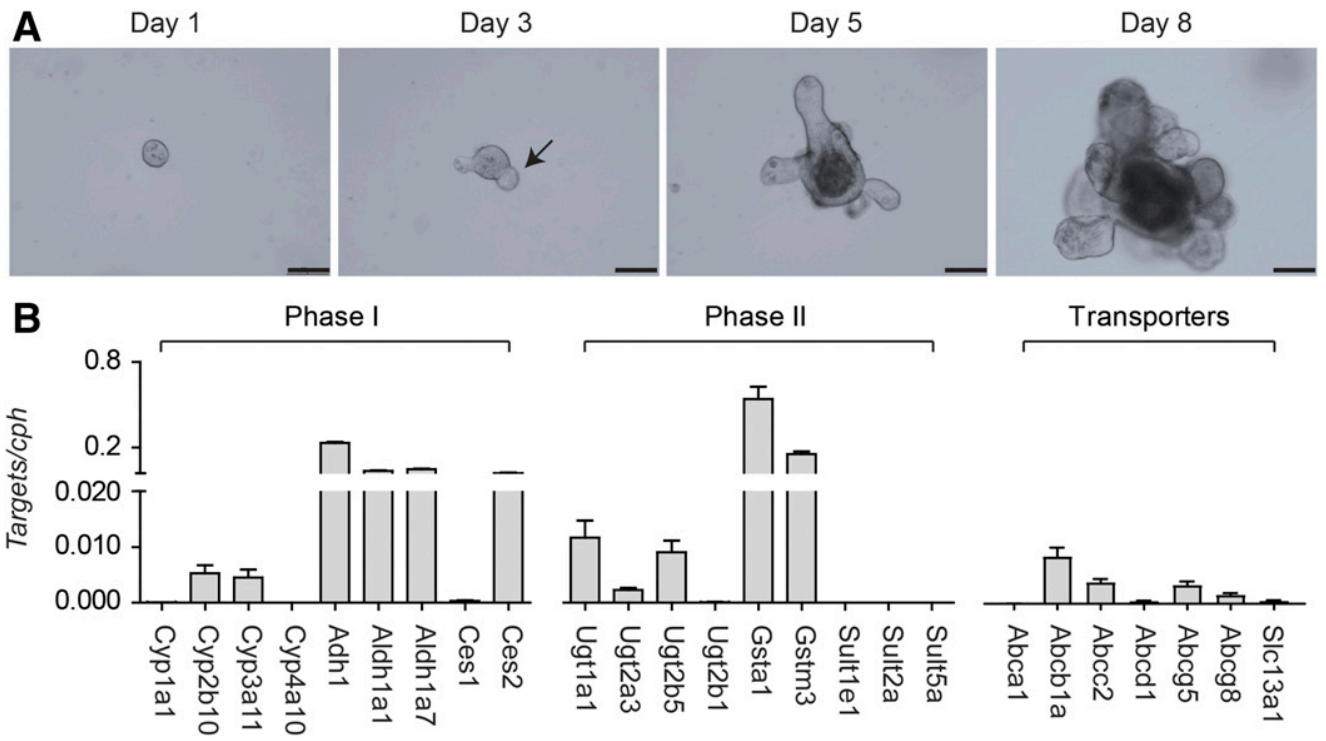

Fig. 1. The growth of small intestinal crypt organoids and the expressions of XPGs in mature crypt organoids. (A) Shown are mouse small intestinal crypt organoid cultures at various times after primary culture. Images were taken with a Nikon Eclipse Ts2 inverted microscope, with the scale bar shown at $90 \mu \mathrm{m}$. (B) Mature crypt organoids (in triplicate) were collected 8 days after plating and RNA prepared for RT-qPCR analysis. Gene expression of Phase I and Phase II drug metabolism genes and transporters are expressed as Target genes/mouse Cph and are described as average \pm S.E.M. $(n=3)$. Data represent multiple independent experiments with similar results.

expression for Cyp2b10 and Cyp3a11 along with other XPGs including alcohol dehydrogenase Adh1, aldehyde dehydrogenase Aldhla1, and Aldhla7 were actively expressed, all of which have been known to exhibit high expression levels in intestine (Vaglenova et al., 2003; Huang et al., 2009; Renaud et al., 2011). In comparison with carboxylesterase (Ces) 1, Ces2 is known as the intestinal specific isoform (Hatfield et al., 2011), which is consistent with our results, although RT-qPCR results cannot provide absolute gene expression levels. Phase II XPGs were highlighted by gene expression of Gst in addition to the $U g t s$ encoded by the $U g t 1$ and $U g t 2$ gene families, both of which are intestinal enriched genes (Gibbs et al., 1998; Strassburg et al., 1999; Shin et al., 2009). Efflux drug transporters were also identified in crypt organoids, such as P-glycoprotein (Pgp, Abcbla) and Mrp2 $(A b c c 2)$, both of which are important transporters of many drugs and xenobiotics in enterocytes (Sparreboom et al., 1997; Mottino et al., 2000), along with intestinal specific transporters Abcg5/8 (Berge et al., 2000), which are important sterol efflux pumps.

Functional Nuclear Receptors Observed in Organoids that Respond to Xenobiotic Treatment. Fundamental to understanding the regulatory events associated with DMEs has been a clear vision characterizing the role of the xenobiotic nuclear receptors (XNRs) in control and expression of the xenobiotic processing genes (XPGs) (Rushmore and Kong, 2002; Staudinger et al., 2010, 2013; Chai et al., 2013; Hoffmann and Partridge, 2015). Xenobiotic and environmental toxicant exposure has the potential to modify XPG expression through interactions with XNRs. Altered gene expression through activation of XNRs affects drug metabolism as well as drug-drug interactions, leading to changes in drug efficacy and safety. The gene expression levels of XNRs in crypt organoids were determined, as shown in Fig. 2A. We examined expression of the genes encoding the aryl hydrocarbon receptor $(A h r)$, pregnane $\mathrm{X}$ receptor $(P x r)$, constitutive androstane receptor $(\mathrm{Car})$, peroxisome proliferator-activated receptors (Ppar), retinoid $\mathrm{X}$ receptor $(R x r)$, and the liver $\mathrm{X}$ receptor $(L x r)$, and RNA encoded by each gene was detectable. These gene expression patterns are relative to $C p h$ gene expression and do not reflect comparative expression values of RNA between the genes, because the primers for each gene may have differences in their annealing properties. To determine their functionality, crypt organoids were then treated with specific XNR ligands and downstream target gene expression evaluated. TCDD treatment, the prototypical agonist of the aryl hydrocarbon receptor (AhR) (Quattrochi and Tukey, 1993), induced Cyplal gene expression (Fig. 2B); BNF, an AhR agonist (Sinal et al., 1999), also induced Cyplal (Fig. 2B). Similarly, when crypt organoids were treated with TCPOBOP, a mouse-specific CAR agonist (Tzameli et al., 2000), Cyp 2 b10 was induced (Fig. 2C). Cyp3a11 gene expression was induced by PCN (Fig. 2D), a well-studied PXR ligand (Guo et al., 2002). We observed that Cyp3a11 was also induced by TCPOBOP and the LXR agonist T0901317 (N-(2,2,2-Trifluoroethyl)-N-[4-[2,2,2-trifluoro-1hydroxy-1-(trifluoromethyl)ethyl]phenyl]benzenesulfonamide), implying that Cyp3a11 gene expression can also be regulated by activated CAR and LXR. Cyp4a10 was largely induced by the PPAR $\alpha$ agonist WY14643 (Fig. 2E). Drug transporter genes were also inducible, as shown in Fig. 2F, with induction of Abcal gene expression by the LXR agonist T0901317.

Crypt Organoids Isolated from XNR-knockout Mice for XPG Expression Studies. Knockout (KO) mouse models have been used to understand the physiological and pharmacological role of a specific gene. Knockout mouse models have also been exploited in drug metabolism studies, particularly in elucidating XNR-mediated gene regulation of XPGs. Here we have used both global and intestinalspecific KO mouse models to investigate the use of organoid cultures in drug metabolism studies. Crypt cells were isolated from both wild-type and Para $^{-1-}$ mice, and after 5 days the organoids were treated with breast milk (1:100 dilution), the fatty acid DHA at $5 \mu \mathrm{M}$, and the $\operatorname{PPAR} \alpha$ agonist WY14643 at $100 \mu \mathrm{M}$. Twenty-four hours after treatment, cells were collected for RT-qPCR analysis. In wild-type cells, breast milk, DHA, and WY14643 activated gene expression of the PPAR $\alpha$-targeted gene Cyp4a10; however, these inductions were completely diminished in crypt organoids isolated from Ppard $^{-/-}$mice (Fig. $3 \mathrm{~A})$. Similarly, PCN also lost its capability in mediating the Cyp3a11 induction in $\mathrm{Pxr}^{-1-}$ organoids (Fig. 3B). These results confirm that crypt organoids maintain the genetic characteristics that are exhibited in $\mathrm{KO}$ mice following activation of XNRs. 

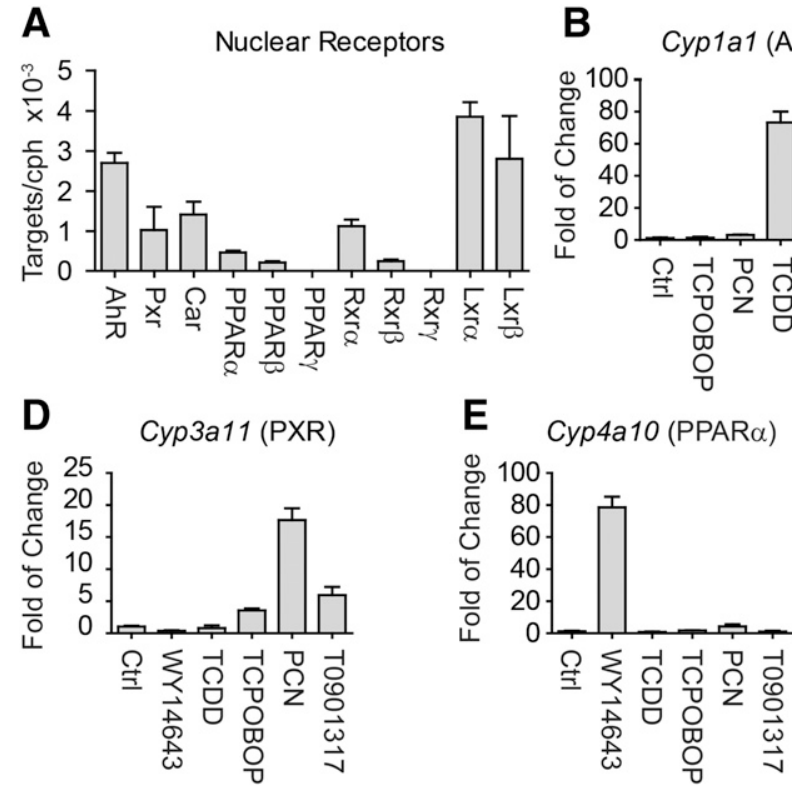
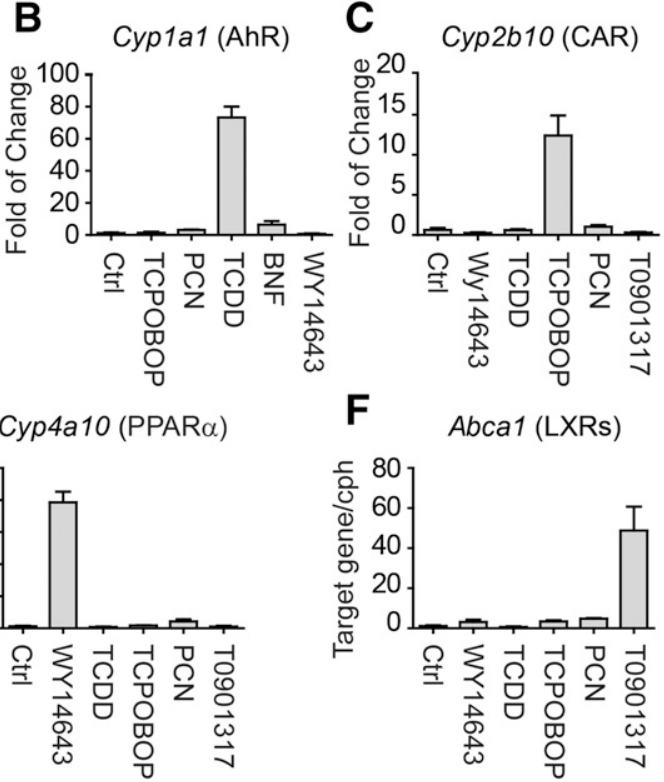

Fig. 2. Gene expression analysis of NRs and their function in mature crypt cells. (A) Shown are nuclear receptor expression levels from mature crypt cells conducted by RT-qPCR analysis, average \pm S.E.M. $(n=3)$. (B-F) Crypts in exponential growth period were treated with different nuclear receptor agonists, including TCDD (50 nM), $\beta$-Naphthoflavone $(\beta \mathrm{NF})$ (20 $\mu \mathrm{M})$, TCPOBOP $(10 \mu \mathrm{M})$, PCN $(30 \mu \mathrm{M})$, T0901317 $(100 \mu \mathrm{M})$, and WY14643 $(100 \mu \mathrm{M})$. Twenty-four hours after agonist exposure, crypt cells were collected for RT-qPCR analysis (average \pm S.E.M., experiments carried out in triplicate).
Intestinal Crypt Cultures Metabolize CPT-11. Stable crypt organoids express CES1 and 2, UGT1A1, and the transporters ABCC2 and $\mathrm{ABCB} 1 \mathrm{~A}$ based upon gene expression analysis. CPT-11 enters intestinal epithelial cells and is cleaved by CES to the active topoisomerase inhibitor $\mathrm{SN}-38$, a product that is toxic and damaging to tissues if not metabolized further by glucuronidation. To determine if intestinal crypt cultures could metabolize CPT-11 and culminate with the formation of the $\mathrm{SN}-38$ glucuronide $(\mathrm{SN}-38 \mathrm{G})$, cells were first treated with a range of CPT-11 concentrations (Fig. 4A). After exposure for 24 hours, culture media (extracellular) and cells (intracellular) were harvested for quantitation of SN-38 and SN-38G by HPLC-MS analysis. In culture media, as the concentration of CPT-11 was increased there was a concordant increase in $\mathrm{SN}-38$ and $\mathrm{SN}-38 \mathrm{G}$ (Fig. 4A). The concentrations of SN-38 fit a linear model with R-squared at 0.99, but the SN-38G levels showed poor linearity with R-squared at 0.84 indicating enzymatic saturation (Fig. 4A). As the concentration of CPT-11 is increased, there is the rapid appearance of intracellular SN-38 at $10 \mu \mathrm{M} \mathrm{CPT}-11$ that is nearly triple the concentration of intracellular SN-38G (Fig. 4B), supporting the extracellular values that implicate UGT1A1 saturation. When the ratios of $\mathrm{SN}-38 \mathrm{G} / \mathrm{SN}-38$ were determined in both compartments, the ratios were much higher in the extracellular compartment, indicating that both SN-38 and SN-38G are removed from the cell by efflux transporters (Fig. 4C). The highest concentration of CPT-11 used resulted in a sharp decline in both the extracellular and intracellular SN-38G/SN-38 ratios, indicating that enzymatic cleavage of CPT-11 to SN-38 and the resulting glucuronidation of SN-38 to SN-38G were declining. Because SN-38 is toxic, this result corresponded to an increase in cell death, as demonstrated by induction of cleaved caspase 3, a marker of cell apoptosis (Fig. 4D).

In the absence of glucuronidation, the intestinal epithelium is sensitive to the toxic actions of SN-38 (Chen et al., 2013). When we targeted the deletion the Ugtl locus and the Ugtlal gene in $U g t 1^{\Delta I E C}$ mice and challenged $U g t 1^{\Delta I E C}$ mice with CPT-11, they were highly susceptible to diarrhea in comparison with wild-type $U g t 1^{F / F}$ mice (Chen et al., 2013). Apoptosis was not observed in $U g t 1^{F / F}$ crypt cells when treated with CPT-11 at $1 \mu \mathrm{M}$, but apoptosis was apparent in crypt organoids from $U g t 1^{\Delta I E C}$ mice at this concentration (Fig. 4E), in which cells showed no expression of UGT1 protein (Fig. 4E) and failed to form the metabolite $\mathrm{SN}-38 \mathrm{G}$ (Fig. 4F). Therefore, crypt organoids from $U g t 1^{\Delta I E C}$ mice were at least 10-fold more sensitive to the toxic actions of CPT-11 than $U g t 1^{F / F}$ mice. Crypt organoid cultures can be employed to examine the metabolic outcome of drug and xenobiotic metabolism, the outcome of metabolism
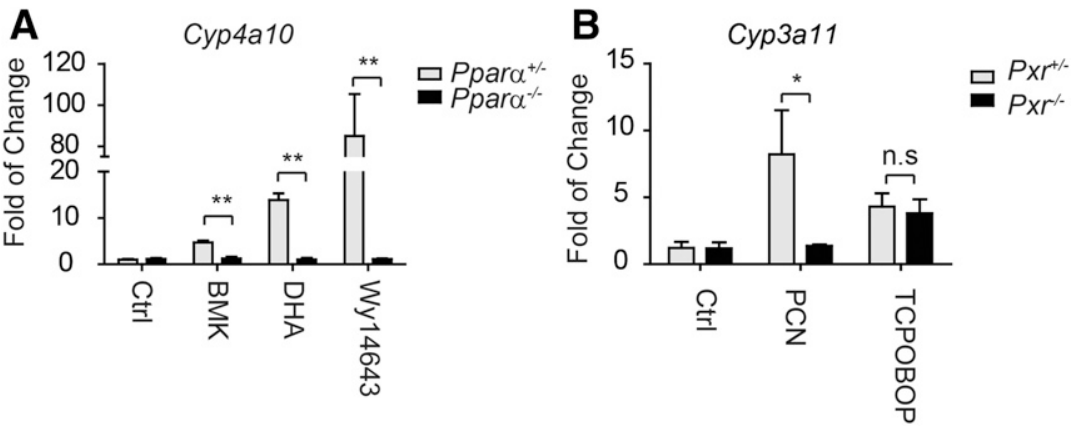

Fig. 3. RT-qPCR results of mature crypt cells from both wildtype and genetically modified mice. (A) Crypt cells were isolated from Ppard $^{+/-}$(wild-type) and Ppard ${ }^{-\prime-}$ (Ppar $\alpha$ deletion) mice. After several passages, crypt cells were treated with vehicle control (Ctrl, DMSO at $0.1 \%)$, breast milk (BMK) at 1:100 (v/v) dilution into the culture medium, DHA $(5 \mu \mathrm{M})$, and WY14643 $(100 \mu \mathrm{M})$ for 24 hours. Cells were collected for RT-qPCR analysis to measure Cyp $4 a 10$ gene expression. Results were normalized with vehicle-treated wild-type crypts and described as fold change (average \pm S.E.M., $n=3$ ). (B) Crypt cells were isolated from wild-type $\mathrm{Pxr}^{+-}$and $\mathrm{Pxr}^{-{ }_{-}}$knockout mice. Cells were treated with PCN at $30 \mu \mathrm{M}$ and TCPOBOP at $10 \mu \mathrm{M}$ for 24 hours followed by Cyp3a11 gene expression analyzed by RT-qPCR $(n=3)$. n.s., Nonsignificant, $* P<0.05, * * P<0.01$, Student's $t$ test. 

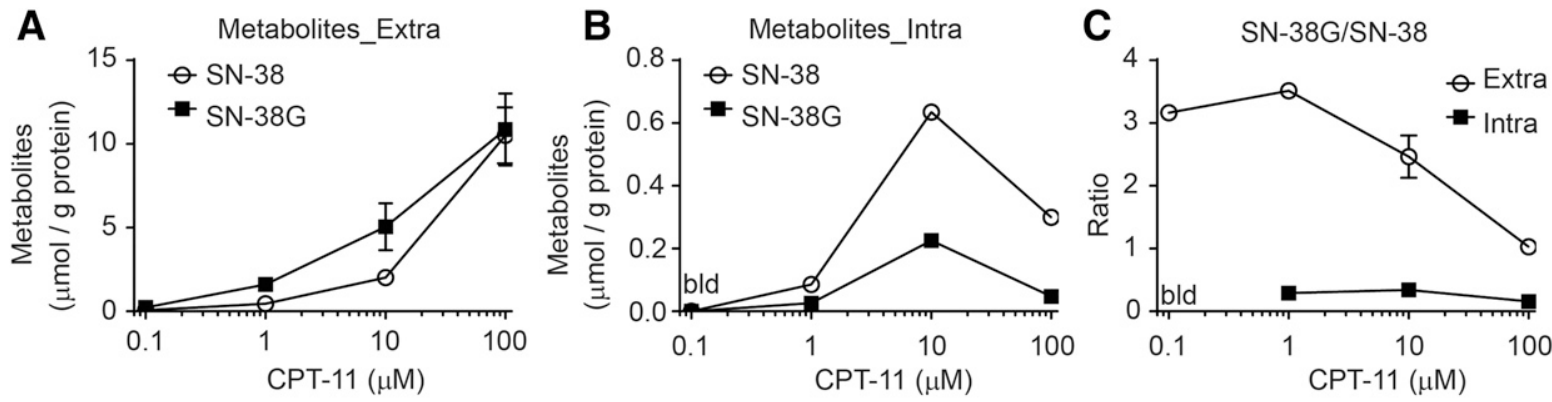

D

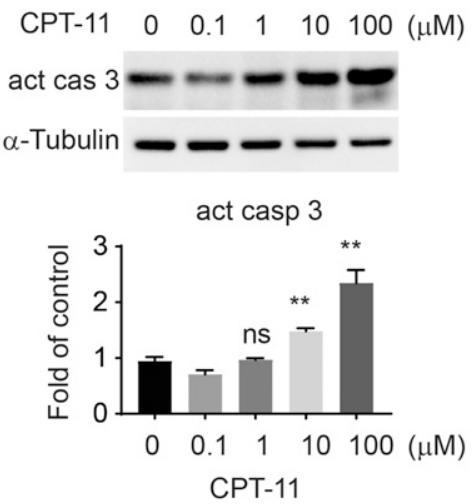

$\mathbf{E}$

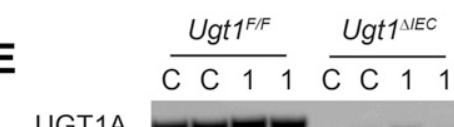

act Cas 3

$\alpha$-Tubulin

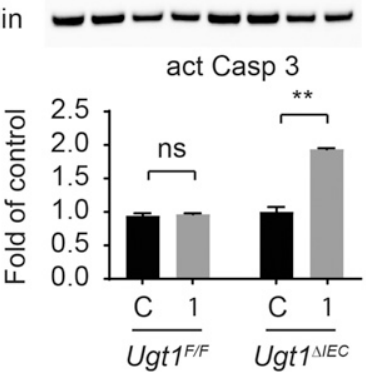

$\mathbf{F}$

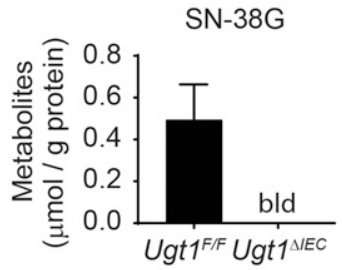

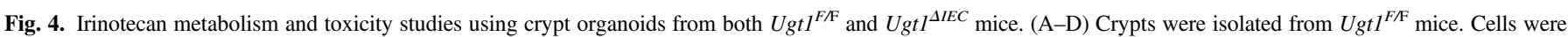

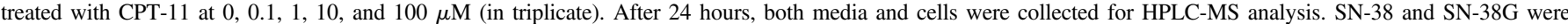

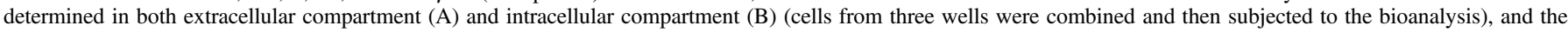

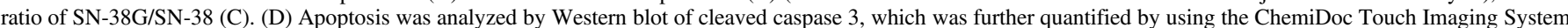

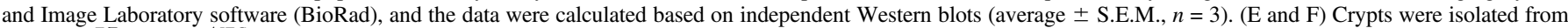

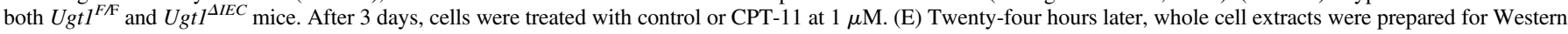

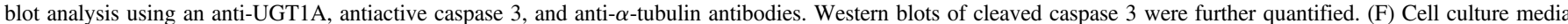
were collected for bioanalysis of SN-38G (average \pm S.E.M., $n=3$ ). bld, Below limit of detection.

following XNR activation, and the disposition of metabolism under conditions of altered pharmacogenetics.

\section{Discussion}

Recent advances in establishing long-term culture conditions of cryptvilli that propagate into functional organoids with intact luminal surfaces have made it possible to investigate intestinal epithelial cell functionality in tissue culture (Sato et al., 2009; Sato and Clevers, 2013). Because intestinal epithelial cells turn over in adults, for example, every 5 days in mice, new epithelial cells are formed from long-lived intestinal stem cells (ISCs) that sit at the base of the crypts (Barker et al., 2008). These stem cells produce the rapidly proliferating progenitor cells called transit-amplifying cells that migrate up the crypt-villus axis and eventually differentiate into mature epithelial cells. With discovery of the signaling pathways that are necessary to maintain stemness leading to epithelial cell proliferation, environmental cues have been employed to promote the crypt ISCs to form mini-gut cultures that are composed of budding epithelial cells (Sato et al., 2009,2011; Sato and Clevers, 2013). These three-dimensional mini-gut organoid cultures resemble in vivo intestinal epithelial structures, with a single ISC producing the different types of differentiated cells needed to support the development of the mature enterocytes (Sato et al., 2009,2011). It has also been demonstrated that the organoids maintain absorptive and digestive functions, making the tissue an excellent model to examine drug uptake and metabolism and the impact of xenobiotic exposure on epithelial cell function. Taking advantage of this unique physiology, we explored the use of three-dimensional mini-gut organoids to examine XPG expression, inducibility, and metabolism.

Within 8 days of culturing crypt stem cells, the expanding organoids show well-structured epithelial cell projections. Constitutive expression of XPGs was abundant, with those encoding the classically identified Phase 1, Phase II, and Phase III (transporters) genes well represented. The culture medium contains high concentrations of $\mathrm{N}$-acetylcysteine, which is a substrate in the synthesis of glutathione (Weinander et al., 1994). Elevated glutathione concentrations provide a rich reductive capacity for the cell, indicating that organoid cultures may be an excellent model to examine receptor-mediated induction of XPGs by drugs and xenobiotics without producing excessive oxidative stress. The major XNRs that are targeted for activation by drugs and xenobiotics are also expressed and include the AhR, PXR, CAR, PPAR $\alpha$, and LXR, which are key modulators of gene expression that often control the balance between exposures, resulting in a toxic or efficacious outcome. Expression of the XNRs is functional in the proliferating organoids, as we demonstrated by receptor-mediated induction of key genes linked to drug transport and metabolism. Similar results were recently demonstrated (Bijsmans et al., 2017). There was high specificity for activation of the AhR by TCDD and induction of Cyplal gene expression (Strom et al., 1992). Although BNF is an agonist of the AhR, it also induces Cypla1, but the response is not as potent as TCDD (Sinal et al., 1999). Interestingly, we did not notice any unusual growth inhibition properties of our proliferating organoids following TCDD treatment as was noted in a recent publication examining growth properties following activation of the AhR (Park et al., 2016). These differences may result from the 
concentrations of TCDD used; although we found excellent induction using $50 \mathrm{nM}$, Park et al. (2016) treated their organoid preparations with 0.1 to $1.0 \mu \mathrm{M}$. The mouse Cyp2b10 gene is selectively induced by mouse-specific CAR ligands (Honkakoski et al., 1998). Activation of PXR by PCN generates robust induction of Cyp3all gene expression. Activation of CAR has been shown previously to induce Cyp3a11 (Hernandez et al., 2009), corroborating our results with crypt organoids demonstrating induction of Cyp3all gene expression by the CAR activator TCPOBOP. This is further supported when crypt organoids deficient in PXR exhibit elevated Cyp3a11 gene expression when treated with TCPOBOP. In addition, activation of LXR by T0901317, which targets activation of Abcal gene expression (Wagner et al., 2003), can also support induction of Cyp3a11 gene expression. These findings indicate that Cyp3al1 can be regulated following activation of PXR, CAR, and LXR. We showed previously that oral administration to mice with the PPAR $\alpha$ agonist WY14643 induces intestinal CYP4A protein expression (Senekeo-Effenberger et al., 2007). Significant activation of Cyp4a10 gene expression in organoid cultures is also documented following exposure with WY14643, a response that is eliminated in cultures derived from PPAR $\alpha$-null mice.

The functionality of the crypt organoid cultures can be exploited for metabolism and toxicology studies by implementing cultures derived from XNR and XPG knockout mice. We demonstrated this capability using $U g t 1^{\Delta I E C}$ mice, where we have targeted the specific deletion of the Ugtl locus in intestinal epithelial cells. These mice are deficient in the UGT1A proteins, including UGT1A1. Characteristic of crypt organoids and intestinal epithelial cells, they express CES2, necessary to cleave the prodrug CPT-11 to $\mathrm{SN}-38$, the active topoisomerase 1 inhibitor. The high expression levels of CES2 are an excellent example that documents the maintenance of tissue-specific expression markers that can be exploited to examine drug metabolism. It supports previous reports from Clevers' laboratory (Sato et al., 2009; Sato and Clevers, 2013) and more recently the van Mills group (Bijsmans et al., 2017) that gene expression profiles in intestinal organoids resemble patterns observed in normal tissue. We showed previously in $U g t 1^{\Delta I E C}$ mice that treatment with CPT-11 led to severe intestinal damage, resulting from the efficient generation of SN-38 coupled with the inability to generate UGT1A1dependent SN-38G (Chen et al., 2013). Organoids generated from $U_{g t 1}{ }^{F / F}$ mice efficiently generated $\mathrm{SN}-38$ and $\mathrm{SN}-38 \mathrm{G}$, with cell apoptosis being evident at 10 to $100 \mu \mathrm{M}$ CPT-11. When organoids from $U g t 1^{\triangle I E C}$ mice were treated with the same concentrations of CPT-11, remarkable cell apoptosis was evident at $1 \mu \mathrm{M} \mathrm{CPT-11.}$ These findings provide evidence that examining drug metabolism in crypt organoids can be efficiently linked to specific XPGs while confirming a mechanistic link between gene expression and toxicity.

In conclusion, crypt organoids maintain functional, tissue-specific gene expression encoding DMEs and can be further regulated following activation of XNRs. Crypt organoids developed from stem cells isolated from genetically modified mice maintain their engineered phenotypical features, as determined at both the gene expression and functional levels. It is argued that the use of organoid cultures may eventually reduce the need for animal models in scientific research, because the cultures maintain tissue-specific gene expression that can be regulated following activation of XNRs (Clevers, 2013; Bijsmans et al., 2017). Although the organoid cultures are a superior model when compared with primary cells or long-term differentiated cells, there will always be the need for drug testing in vivo. An example of this need is to define the mechanisms leading to regulation of intestinal UGT1A1 gene expression during development. Neonatal jaundice and severe forms of neonatal hyperbilirubinemia develop because of delayed expression of the UGT1A1 gene during development, and its expression in the GI tract is critical in preventing bilirubin toxicity. Agents that activate many of the XNRs when given orally to neonatal $h U G T 1$ mice induce intestinal UGT1A1 and reduce serum bilirubin. These same agents can induce the UGT1Al gene in tissue culture. However, we discovered that intestinal UGT1A1 gene expression is very responsive to agents that induce mild oxidative stress (Liu et al., 2016). This new mechanism, which can be replicated only in vivo, may lead to the identification of new agents or therapeutics that may be considered as new therapy in the future to prevent the substantial mortality and permanent morbidities resulting from severe neonatal hyperbilirubinemia, which is estimated to impact over 1 million newborns every year (Wong et al., 2011; Bhutani et al., 2013). Thus, crypt organoids could become a valuable tool in drug metabolism and toxicity studies to complement those efforts being conducted with humanized and genetically modified mice.

\section{Acknowledgments}

We thank Dr. Kepeng Wang from Dr. Michael Karin's laboratory at UCSD for helping with the crypt organoid culture. We also want to thank Dr. Calvin Kuo, University of Stanford, for the generous gift of the 293-HA-Rspol-Fc cell line for obtaining R-Spondin 1 conditioned medium.

\section{Authorship Contributions}

Participate in research design: Chen.

Conduct experiments: Lu, Rettenmeier, Paszek, Trottier, Barbier, and Chen. Contributed new reagents or analytic tools: Tukey, Trottier, Barbier, and Chen. Performed data analysis: Lu, Rettenmeier, Trottier, Barbier, and Chen.

Wrote and contributed to the writing of the manuscript: Lu, Rettenmeier, Paszek, Yueh, Tukey, Trottier, Barbier, and Chen.

\section{References}

Alimonti A, Gelibter A, Pavese I, Satta F, Cognetti F, Ferretti G, Rasio D, Vecchione A, and Di Palma M (2004) New approaches to prevent intestinal toxicity of irinotecan-based regimens. Cancer Treat Rev 30:555-562.

Barker N, van de Wetering M, and Clevers H (2008) The intestinal stem cell. Genes Dev 22: 1856-1864.

Berge KE, Tian H, Graf GA, Yu L, Grishin NV, Schultz J, Kwiterovich P, Shan B, Barnes R, and Hobbs HH (2000) Accumulation of dietary cholesterol in sitosterolemia caused by mutations in adjacent ABC transporters. Science 290:1771-1775.

Bhutani VK, Zipursky A, Blencowe H, Khanna R, Sgro M, Ebbesen F, Bell J, Mori R, Slusher TM, Fahmy N, et al. (2013) Neonatal hyperbilirubinemia and Rhesus disease of the newborn: incidence and impairment estimates for 2010 at regional and global levels. Pediatr Res $\mathbf{7 4}$ (Suppl 1):86-100.

Bijsmans IT, Milona A, Ijssennagger N, Willemsen EC, Ramos Pittol JM, Jonker JW, Lange K, Hooiveld GJ, and van Mil SW (2017) Characterization of stem cell-derived liver and intestinal organoids as a model system to study nuclear receptor biology. Biochim Biophys Acta 1863: 687-700.

Chai X, Zeng S, and Xie W (2013) Nuclear receptors PXR and CAR: implications for drug metabolism regulation, pharmacogenomics and beyond. Expert Opin Drug Metab Toxicol 9: 253-266.

Chen S, Yueh MF, Bigo C, Barbier O, Wang K, Karin M, Nguyen N, and Tukey RH (2013) Intestinal glucuronidation protects against chemotherapy-induced toxicity by irinotecan (CPT-11). Proc Natl Acad Sci USA 110:19143-19148.

Clevers H (2013) The intestinal crypt, a prototype stem cell compartment. Cell 154:274-284.

Gibbs JP, Yang JS, and Slattery JT (1998) Comparison of human liver and small intestinal glutathione S-transferase-catalyzed busulfan conjugation in vitro. Drug Metab Dispos 26:52-55. Grabinger T, Luks L, Kostadinova F, Zimberlin C, Medema JP, Leist M, and Brunner T (2014) Ex vivo culture of intestinal crypt organoids as a model system for assessing cell death induction in intestinal epithelial cells and enteropathy. Cell Death Dis 5:e1228.

Guo GL, Staudinger J, Ogura K, and Klaassen CD (2002) Induction of rat organic anion transporting polypeptide 2 by pregnenolone-16alpha-carbonitrile is via interaction with pregnane $\mathrm{X}$ receptor. Mol Pharmacol 61:832-839.

Hatfield MJ, Tsurkan L, Garrett M, Shaver TM, Hyatt JL, Edwards CC, Hicks LD, and Potter PM (2011) Organ-specific carboxylesterase profiling identifies the small intestine and kidney as major contributors of activation of the anticancer prodrug CPT-11. Biochem Pharmacol 81: $24-31$.

Hernandez JP, Mota LC, Huang W, Moore DD, and Baldwin WS (2009) Sexually dimorphic regulation and induction of $\mathrm{P} 450$ s by the constitutive androstane receptor (CAR). Toxicology 256:53-64.

Hoffmann JM and Partridge L (2015) Nuclear hormone receptors: Roles of xenobiotic detoxification and sterol homeostasis in healthy aging. Crit Rev Biochem Mol Biol 50:380-392 Honkakoski P, Zelko I, Sueyoshi T, and Negishi M (1998) The nuclear orphan receptor CARretinoid $\mathrm{X}$ receptor heterodimer activates the phenobarbital-responsive enhancer module of the CYP2B gene. Mol Cell Biol 18:5652-5658.

Huang EH, Hynes MJ, Zhang T, Ginestier C, Dontu G, Appelman H, Fields JZ, Wicha MS, and Boman BM (2009) Aldehyde dehydrogenase 1 is a marker for normal and malignant human colonic stem cells (SC) and tracks SC overpopulation during colon tumorigenesis. Cancer Res 69:3382-3389. 
Iyer L, King CD, Whitington PF, Green MD, Roy SK, Tephly TR, Coffman BL, and Ratain MJ (1998) Genetic predisposition to the metabolism of irinotecan (CPT-11). Role of uridine diphosphate glucuronosyltransferase isoform $1 \mathrm{~A} 1$ in the glucuronidation of its active metabolite (SN-38) in human liver microsomes. $J$ Clin Invest 101:847-854

Kaneda N, Nagata H, Furuta T, and Yokokura T (1990) Metabolism and pharmacokinetics of the camptothecin analogue CPT-11 in the mouse. Cancer Res 50:1715-1720.

Lee SS, Pineau T, Drago J, Lee EJ, Owens JW, Kroetz DL, Fernandez-Salguero PM, Westphal H, and Gonzalez FJ (1995) Targeted disruption of the alpha isoform of the peroxisome proliferatoractivated receptor gene in mice results in abolishment of the pleiotropic effects of peroxisome proliferators. Mol Cell Biol 15:3012-3022.

Liu M, Chen S, Yueh MF, Fujiwara R, Konopnicki C, Hao H, and Tukey RH (2016) Cadmium and arsenic override NF- $\mathrm{kB}$ developmental regulation of the intestinal UGT1A1 gene and control of hyperbilirubinemia. Biochem Pharmacol 110-111:37-46.

Marangon E, Posocco B, Mazzega E, and Toffoli G (2015) Development and validation of a highperformance liquid chromatography-tandem mass spectrometry method for the simultaneous determination of irinotecan and its main metabolites in human plasma and its application in a clinical pharmacokinetic study. PLoS One 10:e0118194.

Michael M, Thompson M, Hicks RJ, Mitchell PL, Ellis A, Milner AD, Di Iulio J, Scott AM, Gurtler V, Hoskins JM, et al. (2006) Relationship of hepatic functional imaging to irinotecan pharmacokinetics and genetic parameters of drug elimination. J Clin Oncol 24:4228-4235.

Mottino AD, Hoffman T, Jennes L, and Vore M (2000) Expression and localization of multidrug resistant protein mrp2 in rat small intestine. J Pharmacol Exp Ther 293:717-723.

Ootani A, Li X, Sangiorgi E, Ho QT, Ueno H, Toda S, Sugihara H, Fujimoto K, Weissman IL, Capecchi MR, et al. (2009) Sustained in vitro intestinal epithelial culture within a Wnt-dependent stem cell niche. Nat Med 15:701-706.

Park JH, Choi AJ, Kim SJ, Cheong SW, and Jeong SY (2016) AhR activation by 6-formylindolo[3,2-b]carbazole and 2,3,7,8-tetrachlorodibenzo-p-dioxin inhibit the development of mouse intestinal epithelial cells. Environ Toxicol Pharmacol 43:44-53.

Quattrochi LC and Tukey RH (1993) Nuclear uptake of the Ah (dioxin) receptor in response to omeprazole: transcriptional activation of the human CYP1A1 gene. Mol Pharmacol 43:504-508.

Ranga A, Gjorevski N, and Lutolf MP (2014) Drug discovery through stem cell-based organoid models. Adv Drug Deliv Rev 69-70:19-28.

Renaud HJ, Cui JY, Khan M, and Klaassen CD (2011) Tissue distribution and gender-divergent expression of 78 cytochrome P450 mRNAs in mice. Toxicol Sci 124:261-277.

Rushmore TH and Kong AN (2002) Pharmacogenomics, regulation and signaling pathways of phase I and II drug metabolizing enzymes. Curr Drug Metab 3:481-490.

Sato T and Clevers H (2013) Growing self-organizing mini-guts from a single intestinal stem cell: mechanism and applications. Science 340:1190-1194.

Sato T, van Es JH, Snippert HJ, Stange DE, Vries RG, van den Born M, Barker N, Shroyer NF, van de Wetering M, and Clevers H (2011) Paneth cells constitute the niche for Lgr5 stem cells in intestinal crypts. Nature 469:415-418.

Sato T, Vries RG, Snippert HJ, van de Wetering M, Barker N, Stange DE, van Es JH, Abo A, Kujala P, Peters PJ, et al. (2009) Single Lgr5 stem cells build crypt-villus structures in vitro without a mesenchymal niche. Nature 459:262-265.

Senekeo-Effenberger K, Chen S, Brace-Sinnokrak E, Bonzo JA, Yueh MF, Argikar U, Kaeding J, Trottier J, Remmel RP, Ritter JK, et al. (2007) Expression of the human UGT1 locus in transgenic mice by 4-chloro-6-(2,3-xylidino)-2-pyrimidinylthioacetic acid (WY-14643) and implications on drug metabolism through peroxisome proliferator-activated receptor alpha activation. Drug Metab Dispos 35:419-427.

Shin HC, Kim HR, Cho HJ, Yi H, Cho SM, Lee DG, Abd El-Aty AM, Kim JS, Sun D, and Amidon GL (2009) Comparative gene expression of intestinal metabolizing enzymes. Biopharm Drug Dispos 30:411-421.

Sinal CJ, Webb CD, and Bend JR (1999) Differential in vivo effects of alpha-naphthoflavone and beta-naphthoflavone on CYP1A1 and CYP2E1 in rat liver, lung, heart, and kidney. J Biochem Mol Toxicol 13:29-40.

Sparreboom A, van Asperen J, Mayer U, Schinkel AH, Smit JW, Meijer DK, Borst P, Nooijen WJ, Beijnen JH, and van Tellingen O (1997) Limited oral bioavailability and active epithelial excretion of paclitaxel (Taxol) caused by P-glycoprotein in the intestine. Proc Natl Acad Sci USA 94:2031-2035.

Staudinger JL, Woody S, Sun M, and Cui W (2013) Nuclear-receptor-mediated regulation of drugand bile-acid-transporter proteins in gut and liver. Drug Metab Rev 45:48-59.

Staudinger JL, Xu C, Cui YJ, and Klaassen CD (2010) Nuclear receptor-mediated regulation of carboxylesterase expression and activity. Expert Opin Drug Metab Toxicol 6:261-271.

Strassburg CP, Nguyen N, Manns MP, and Tukey RH (1999) UDP-glucuronosyltransferase activity in human liver and colon. Gastroenterology 116:149-160.

Strom DK, Postlind H, and Tukey RH (1992) Characterization of the rabbit CYP1A1 and CYP1A2 genes: developmental and dioxin-inducible expression of rabbit liver P4501A1 and P4501A2. Arch Biochem Biophys 294:707-716.

Sugimoto Y, Tsukahara S, Oh-hara T, Isoe T, and Tsuruo T (1990) Decreased expression of DNA topoisomerase I in camptothecin-resistant tumor cell lines as determined by a monoclonal antibody. Cancer Res 50:6925-6930.

Tzameli I, Pissios P, Schuetz EG, and Moore DD (2000) The xenobiotic compound 1,4-bis[2-(3,5 dichloropyridyloxy)]benzene is an agonist ligand for the nuclear receptor CAR. Mol Cell Biol 20:2951-2958.

Ueda A, Hamadeh HK, Webb HK, Yamamoto Y, Sueyoshi T, Afshari CA, Lehmann JM, and Negishi M (2002) Diverse roles of the nuclear orphan receptor CAR in regulating hepatic genes in response to phenobarbital. Mol Pharmacol 61:1-6.

Vaglenova J, Martínez SE, Porté S, Duester G, Farrés J, and Parés X (2003) Expression, localization and potential physiological significance of alcohol dehydrogenase in the gastrointestinal tract. Eur J Biochem 270:2652-2662.

van Herwaarden AE, Wagenaar E, van der Kruijssen CM, van Waterschoot RA, Smit JW, Song JY, van der Valk MA, van Tellingen O, van der Hoorn JW, Rosing H, et al. (2007) Knockout of cytochrome $\mathrm{P} 450$ 3A yields new mouse models for understanding xenobiotic metabolism. J Clin Invest 117:3583-3592

van Waterschoot RA, Rooswinkel RW, Wagenaar E, van der Kruijssen CM, van Herwaarden AE, and Schinkel AH (2009) Intestinal cytochrome P450 3A plays an important role in the regulation of detoxifying systems in the liver. FASEB $J$ 23:224-231.

van Waterschoot RA, van Herwaarden AE, Lagas JS, Sparidans RW, Wagenaar E, van de Kruijssen CM, Goldstein JA, Zeldin DC, Beijnen JH, and Schinkel AH (2008) Midazolam metabolism in cytochrome P450 3A knockout mice can be attributed to up-regulated CYP2C enzymes. Mol Pharmacol 73:1029-1036.

Wagner BL, Valledor AF, Shao G, Daige CL, Bischoff ED, Petrowski M, Jepsen K, Baek SH, Heyman RA, Rosenfeld MG, et al. (2003) Promoter-specific roles for liver X receptor/ corepressor complexes in the regulation of ABCA1 and SREBP1 gene expression. Mol Cell Biol 23:5780-5789.

Weinander R, Anderson C, and Morgenstern R (1994) Identification of N-acetylcysteine as a new substrate for rat liver microsomal glutathione transferase. A study of thiol ligands. J Biol Chem 269:71-76.

Wong RJ, Vreman HJ, Schulz S, Kalish FS, Pierce NW, and Stevenson DK (2011) In vitro inhibition of heme oxygenase isoenzymes by metalloporphyrins. J Perinatol 31 (Suppl 1): S35-S41.

Xie W, Barwick JL, Downes M, Blumberg B, Simon CM, Nelson MC, Neuschwander-Tetri BA, Brunt EM, Guzelian PS, and Evans RM (2000) Humanized xenobiotic response in mice expressing nuclear receptor SXR. Nature 406:435-439.

Yamazaki Y, Kakizaki S, Horiguchi N, Takagi H, Mori M, and Negishi M (2005) Role of nuclear receptor CAR in carbon tetrachloride-induced hepatotoxicity. World J Gastroenterol 11 5966-5972.

Zanger UM, Turpeinen M, Klein K, and Schwab M (2008) Functional pharmacogenetics/genomics of human cytochromes P450 involved in drug biotransformation. Anal Bioanal Chem 392:1093-1108.

Address correspondence to: Dr. Shujuan Chen, 9500 Gilman Drive, La Jolla, CA 92093-0722. E-mail: s18chen@ucsd.edu 